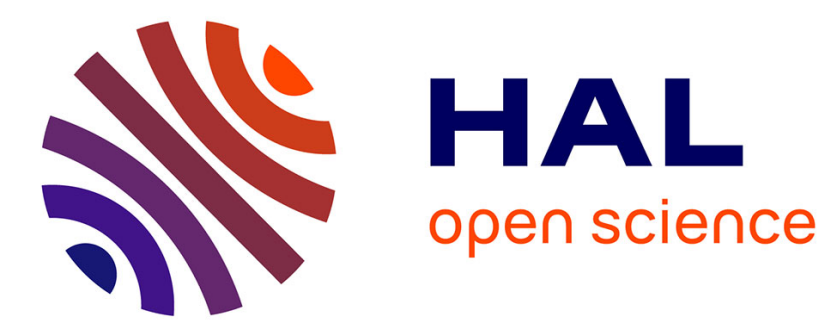

\title{
Excimer laser treatment of ZE41 magnesium alloy for corrosion resistance and microhardness improvement
}

Walid Khalfaoui, Eric Valério, Jean-Eric Masse, Michel Autric

\section{To cite this version:}

Walid Khalfaoui, Eric Valério, Jean-Eric Masse, Michel Autric. Excimer laser treatment of ZE41 magnesium alloy for corrosion resistance and microhardness improvement. Optics and Lasers in Engineering, 2010, 48 (9), pp.926-931. 10.1016/j.optlaseng.2010.03.009 . hal-01060102

\section{HAL Id: hal-01060102 https://hal.science/hal-01060102}

Submitted on 2 Sep 2014

HAL is a multi-disciplinary open access archive for the deposit and dissemination of scientific research documents, whether they are published or not. The documents may come from teaching and research institutions in France or abroad, or from public or private research centers.
L'archive ouverte pluridisciplinaire HAL, est destinée au dépôt et à la diffusion de documents scientifiques de niveau recherche, publiés ou non, émanant des établissements d'enseignement et de recherche français ou étrangers, des laboratoires publics ou privés. 


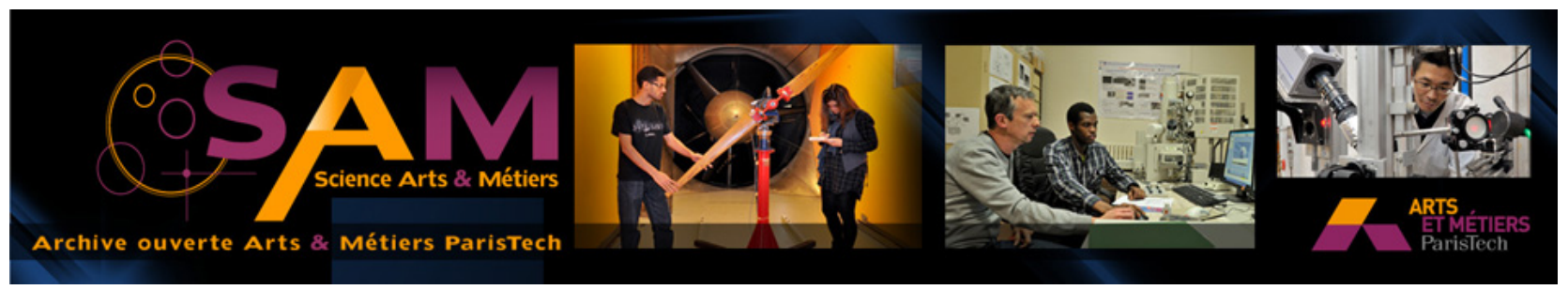

\section{Science Arts \& Métiers (SAM)}

is an open access repository that collects the work of Arts et Métiers ParisTech researchers and makes it freely available over the web where possible.

This is an author-deposited version published in: http://sam.ensam.eu

Handle ID: .http://hdl.handle.net/10985/8442

\section{To cite this version :}

Walid KHALFAOUI, Eric VALÉRIO, Jean-Eric MASSE, Michel AUTRIC - Excimer laser treatment of ZE41 magnesium alloy for corrosion resistance and microhardness improvement - Optics and Lasers in Engineering - Vol. 48, n`9, p.926-931 - 2010 


\title{
Excimer laser treatment of ZE41 magnesium alloy for corrosion resistance and microhardness improvement
}

\author{
Walid Khalfaoui ${ }^{a}$, Eric Valerio ${ }^{\mathrm{a}, *}$, Jean Eric Masse ${ }^{\mathrm{b}}$, Michel Autric ${ }^{\mathrm{a}}$ \\ a IUSTI UMR CNRS 6595, Université de la Méditerranée, Marseille 13453, France \\ ${ }^{\mathrm{b}}$ MECASURF, Ecole Nationale Supérieure d'Arts et Métiers, Aix en Provence 13100, France
}

Keywords:

Laser process

Magnesium alloy ZE41

Laser surface melting

Corrosion

Microhardness

\begin{abstract}
A B S T R A C T
A laser surface melting treatment (LSMT) was performed on a ZE41 Mg-alloy using an excimer KrF laser. The laser-melted layer depth depends on the laser scan speed. The morphology and the microstructure of the laser-melted surface were characterized, thanks to the scanning electron microscopy (SEM). The melted Mg-alloy presented a homogenous distribution of the alloying elements in the magnesium matrix. The laser surface melting treatment increased the microhardness of the ZE41 Mg-alloy and improved its corrosion resistance.
\end{abstract}

\section{Introduction}

Magnesium and its alloys, specially the ZE41, have a wide scope of applications in the fields of aerospace, automotive and many other industries where weight reduction is a concern, because of the low densities and high specific strength of these materials. In fact, magnesium alloys density is only two-thirds of that of aluminum alloys and a quarter of that of steels. Despite the versatility of these alloys, a relatively poor resistance to corrosion and fretting wear makes them less competitive than aluminum alloys [1]. The most common treatments used to improve these properties are chemical surface treatments such as anodization and mordanting process [2]. However these treatments temporarily protect magnesium alloys, they are harmful for the environment and expensive, and there is no doubt that much more efficient protection methods are still needed. Laser surface melting treatment is one of the most interesting materials processings which can enhance the corrosion and wear resistance of ZE41 alloy. LSMT has been reported to increase the wear and corrosion resistance of magnesium alloys [3-11]. Kalimullin et al. [3] reported that LSMT of MA21 alloy makes it possible to increase its corrosion resistance in a $3 \% \mathrm{NaCl}$ solution in comparison with the untreated alloy by about 30 times with pulsed laser treatment and by more than 10 times with continuous laser radiation.

\footnotetext{
* Corresponding author. Tel.: +33603828449; fax: +33491113838.

E-mail address: eric.valerio@univmed.fr (E. Valerio).
}

According to Kalimullin et al., this corrosion resistance improvement is due to the refinement of MA21 grain structure. Koutsomichalis et al. [4] noted that an excimer-laser-treated AZ31B magnesium alloy exhibits higher corrosion resistance in a $\mathrm{NaCl}$ solution and lower microhardness in comparison with the untreated one. Majumdar et al. [6] indicates that LSMT significantly improves the pitting corrosion resistance of MEZ magnesium alloy in a $3.5 \% \mathrm{NaCl}$ solution. It also enhances the microhardness of the alloy by 2-3 times. These improvements are attributed to the combined influence of grain refinement, dissolution of intermetallic phases and retention of alloying elements in an extended solid solution. Abbas et al. [7], Guo et al. [8] and Gao et al. [9] also observed a similar enhancement of corrosion resistance of laser-melted AZ31, AZ61, WE43 and AZ91 Mg-alloys. Jun et al. [10] and Zhang et al. [11] mentioned that both microhardness and wear resistance are improved by respectively $\mathrm{Nd}$ :YAG pulsed and $\mathrm{CO}_{2}$ continuous Laser surface melting treatment of the AM50 and AZ91D magnesium alloys. However, Dubé et al. [5] reported no increase of the corrosion resistance of AZ91D and AM60B alloys in a sodium solution following the use of a pulsed Nd:YAG laser, although refinement of microstructure within the laser-melted layer had been achieved.

Our interest in excimer laser surface melting treatment stems from its ability to produce extremely high power densities $\left(>10^{12} \mathrm{Wm}^{-2}\right.$ ) and the possibility of applying them with precise spatial and temporal control to the processed surface. In addition, the high energy and short pulses of excimer laser associated with 
low reflectivity of metals in the ultraviolet range enable the modification of thin surface layers with a reduced thermal effect in the underlying bulk material. Moreover laser is a clean energy source which does not require a critical environment during processing.

\section{Experimental procedure}

ZE41 specimens with dimensions of $20 \times 20 \times 7 \mathrm{~mm}^{3}$ were cut from the as-cast plate $\left(300 \times 140 \times 15 \mathrm{~mm}^{3}\right)$ which was subjected to a T6-heat treatment (Quench at $300^{\circ} \mathrm{C}$ during $2 \mathrm{~h}$, tempering at $200{ }^{\circ} \mathrm{C}$ during $16 \mathrm{~h}$ ) and was protected by a HAE anodized coating. The chemical composition of a ZE41 alloy is presented in Table 1.

The magnesium specimens were irradiated in atmospheric conditions, without an assisting gas, using a Lambda Physik excimer laser using a $\mathrm{KrF}$ gas mixture. The wavelength of the laser was $\lambda=248 \mathrm{~nm}$ and its pulse duration was $\tau=20 \mathrm{~ns}$. The energy of each pulse and the repetitive rate of pulses were fixed respectively at $E_{\mathrm{p}}=100 \mathrm{~mJ}$ and $F=100 \mathrm{~Hz}$. The laser beam has a rectangular shape with dimensions of $24 \times 10 \mathrm{~mm}^{2}$. To perform laser surface melting treatment, the laser beam was focused thanks to a planoconvex lens with a focal distance of $130 \mathrm{~mm}$. The LSTM was carried over a $1 \times 1 \mathrm{~cm}^{2}$ area in a normal incidence by overlapping several melt tracks with a scan speed $\left(V_{\mathrm{b}}\right)$ varying between 250 and $50 \mu \mathrm{m} \mathrm{s}^{-1}$ and with an overlapping of $50 \%$. (See Fig. 1).

The general features of the melted surfaces were observed through macro photography and optical microscopy. Transverse sections of the laser-melted surfaces were mounted, polished to $1200 \mathrm{SiC}$ and finally etched using a 4\% nital solution before being observed by a scanning electron microscopy (SEM).

The microhardness of the laser-treated and the as-received magnesium alloy was measured using a Leika VMHT Vickers microhardness tester using a load and indentation time respectively equal to $0.49 \mathrm{~N}$ and $15 \mathrm{~s}$.

The corrosion behavior of the as-received and laser-treated magnesium alloy was examined by two methods: the first one consisting in recording the open circuit potentials continuously for $24 \mathrm{~h}$ in $0.5 \mathrm{M} \mathrm{NaCl}$ solution at $\mathrm{pH}=10$ and $293 \mathrm{~K}$ and the second method being the salt-spray test performed as prescribed in the ASTM B 117-97 standard.

Table 1

Chemical composition of ZE41.

\begin{tabular}{llllllll}
\hline Alloying elements & $\mathrm{Zn}$ & $\mathrm{TR}$ & $\mathrm{Zr}$ & $\mathrm{Mn}$ & $\mathrm{Si}$ & $\mathrm{Cu}$ & $\mathrm{Mg}$ \\
\hline \% Weight & 3.21 & 1.23 & 0.83 & 0.013 & 0.009 & 0.04 & 94.668 \\
\hline
\end{tabular}
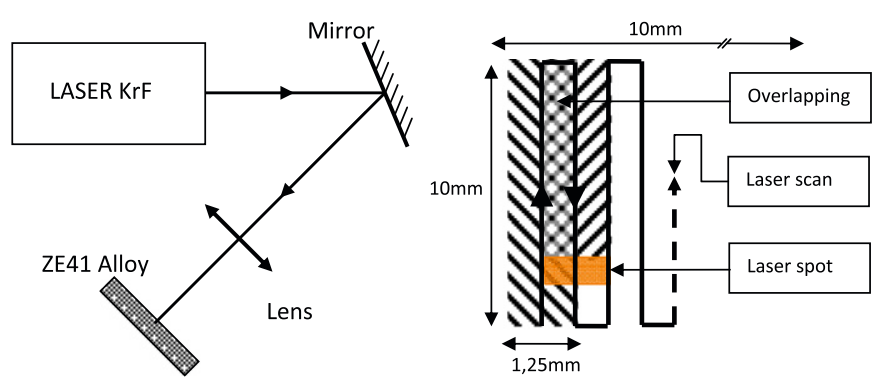

Fig. 1. Schematic diagram of the experimental set-up for laser surface melting of ZE41.

\section{Results and discussion}

The laser surface melting treatments presented below were performed under $100 \mathrm{~mJ}$ pulse energy, $100 \mathrm{~Hz}$ repetitive pulse rate and a scan speed $\left(V_{\mathrm{b}}\right)$ varying between 250 and $50 \mu \mathrm{ms} \mathrm{s}^{-1}$. Laser surface melting treatments were carried out ten times to ensure their repeatability and to provide enough samples for corrosion and microhardness tests. Fig. 2 shows the transverse section of the ZE41 specimen irradiated respectively at 250, 100 and $50 \mu \mathrm{m} \mathrm{s}^{-1}$ scan speeds. The pictures show two zones: the lower one representing the granular structure of the as-received ZE41 specimen. The higher zone is the melted layer. Several measurements of laser-melted layer depth by image processing prove that the layer depth is uniform for each specimen and it is inversely proportional to scan speed. Fig. 3 shows the evolution of the laser-melted layer depth as function of the scan speed.

\subsection{Morphology and microstructure of the laser-melted surfaces}

After the laser surface melting treatment, the ZE41 displayed a complex rippled surface morphology. Fig. 4 shows a wavy morphology: a succession of hollows and hills can be seen on the irradiated surface of the ZE41 specimen. Each hollow corresponds to a laser beam track. Such morphology is due to several causes. The first one is loss of material by evaporation caused by the high power density $\left(160 \mathrm{MW} \mathrm{cm}^{-2}\right)$ of the laser beam. This power density is not homogenous within the laser spot; it reaches the maximum at the centre of the beam and decreases whenever we approach the beam border. Therefore evaporation is emphasized at the centre and a hollow is created. In addition, the high power density brought by the laser pulse creates a temperature gradient around the irradiated zone. This temperature gradient induces a gradient of surface-shear stress, which increases with the distance from the irradiated surface. Consequently, the molten material is pushed away from the irradiation centre towards the beam periphery where the surfaceshear stress is the highest. During laser surface melting treatment, we noticed a creation of plasma on the magnesium alloy surface. The plasma vapours' pressure drives shock waves and compresses the molten material beneath the incident laser beam, enhancing formation of the wavy topography. The irradiated surface is dark and covered with a white powder which can be wiped off. This white powder comes from ionized gas and metal from the plasma which reacts together and form solid products deposited on the magnesium surface as an extremely thin film. The dark thin layer on the irradiated surface is formed by the oxidation of the very hot laser-melted surface.

Fig. 5 shows the transverse section of a ZE41 specimen treated with $E_{\mathrm{p}}=100 \mathrm{~mJ}, F=100 \mathrm{~Hz}$ and $V_{\mathrm{b}}=50 \mu \mathrm{ms}^{-1}$. This section was observed by a scanning electron microscope (SEM) after being mounted, ground to $1200 \mathrm{SiC}$, polished with diamond suspensions to $0.05 \mu \mathrm{m}$ and finally etched using a $4 \%$ nital solution.

As mentioned before, pictures present two zones, the higher one being the laser-melted layer. It has a uniform depth of $70 \mu \mathrm{m}$ $(\operatorname{Max}=73 \mu \mathrm{m}, \operatorname{Min}=69 \mu \mathrm{m})$. The lower zone represents the structure of the as-received ZE41 specimen. This structure is composed of magnesium grains having an average size of $70 \mu \mathrm{m}$ and surrounded by intermetallic compounds, where alloying elements were held. In the laser-melted layer, we cannot observe a crystalline structure because the crystallites are extremely small. We can notice also that there is no intermediary zone between the laser-melted layer and the granular structure because of the rapid heat exchanges during heating and cooling processes. In fact, a small surface of the magnesium alloy absorbs a quantity of the laser energy in an extremely short 


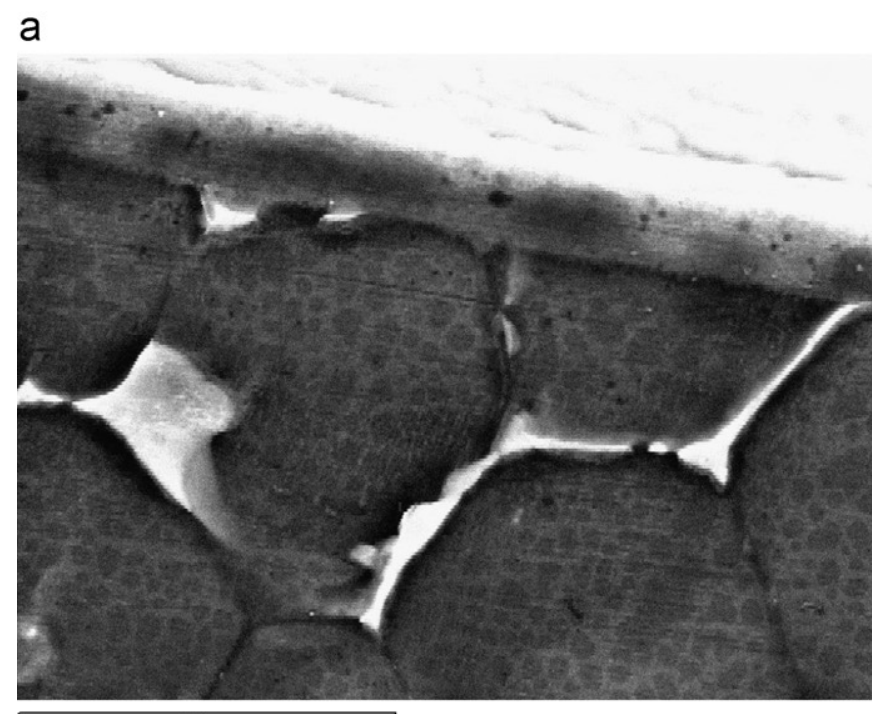

$60 \mu \mathrm{m}$

b
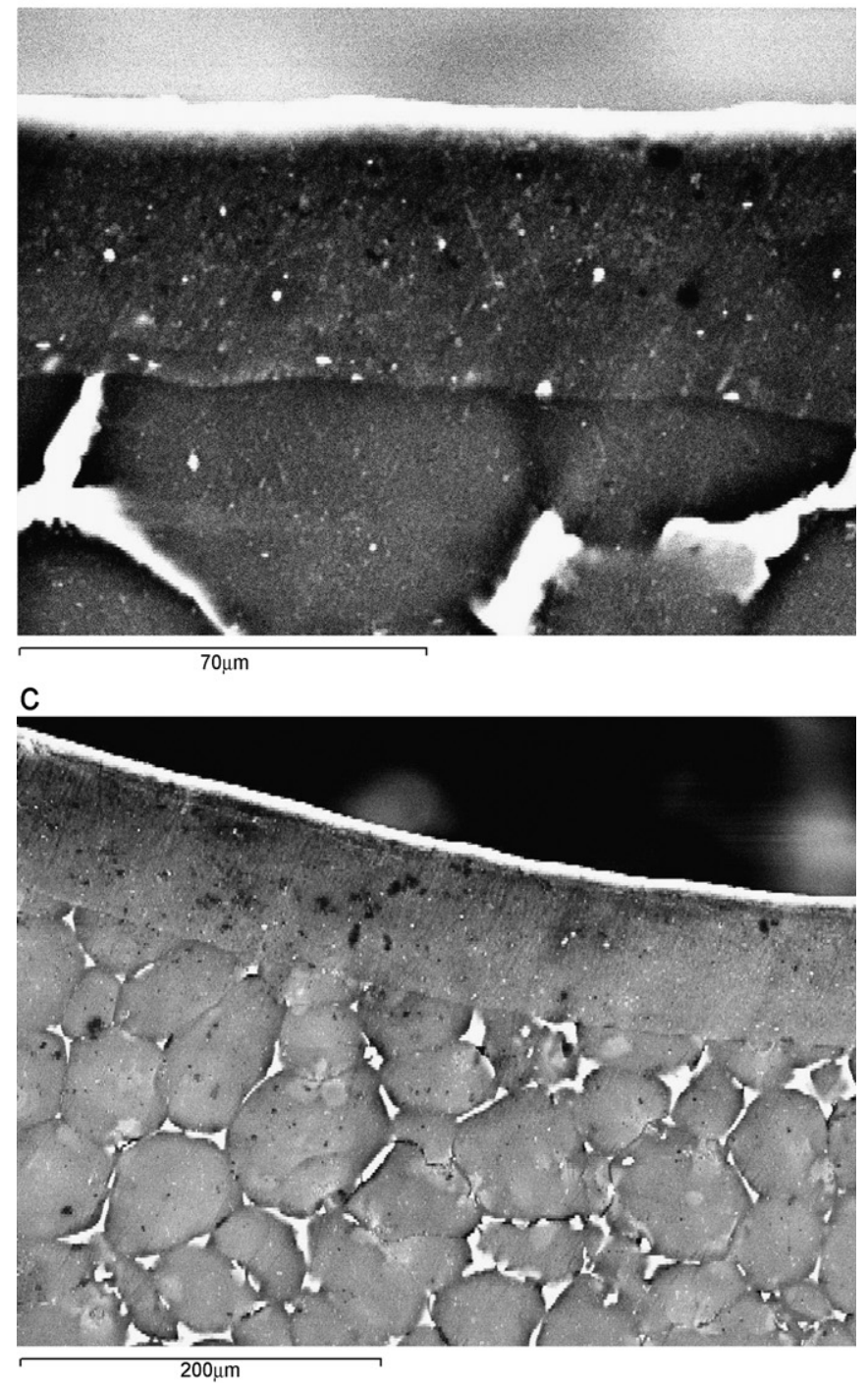

Fig. 2. SEM micrographs of laser-treated surface cross-sections: (a) $V_{\mathrm{b}}=250 \mu \mathrm{m} \mathrm{s}^{-1}$ ( $\times 500),(\mathrm{b}) V_{\mathrm{b}}=100 \mu \mathrm{m} \mathrm{s}^{-1}(\times 500),(\mathrm{c}) V_{\mathrm{b}}=50 \mu \mathrm{m} \mathrm{s}^{-1}(\times 150)$.

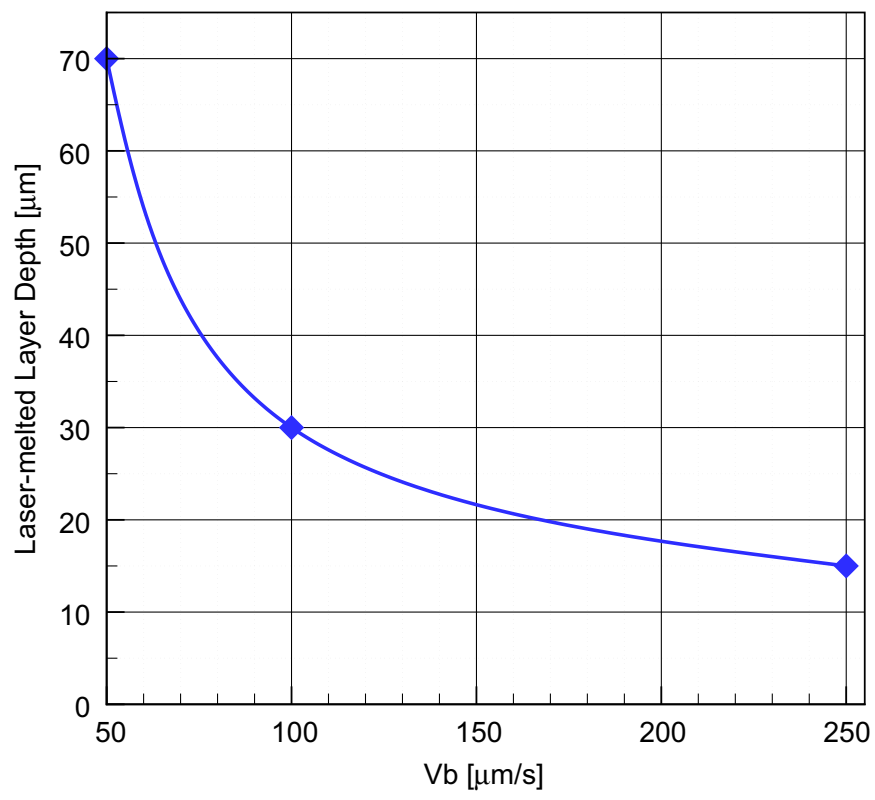

Fig. 3. Evolution of the laser-melted layer depth as function of the scan speed.

a

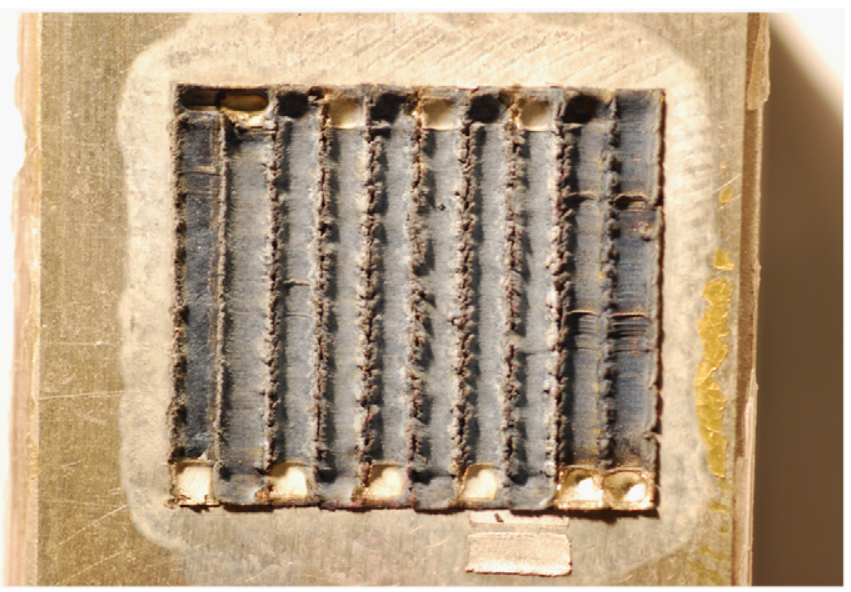

b

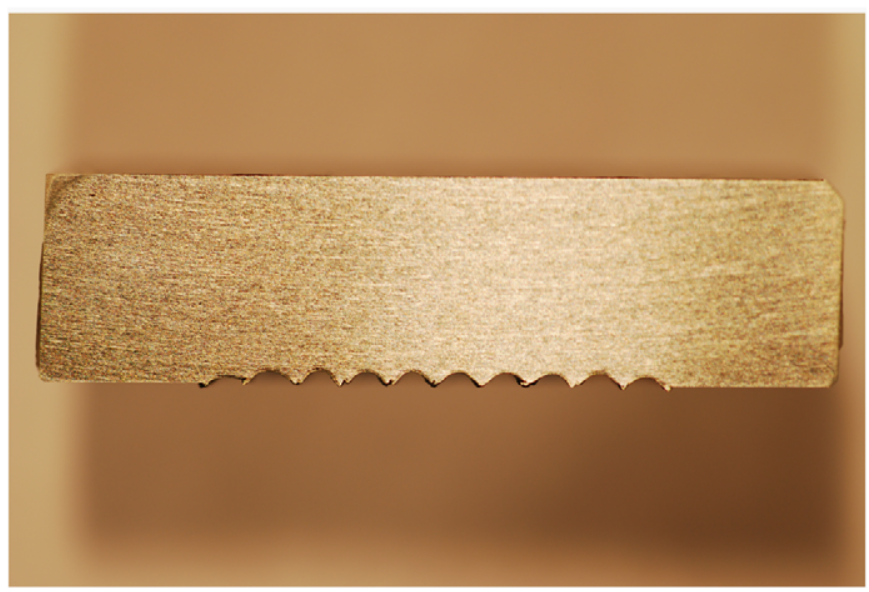

Fig. 4. Morphology of the irradiated surface. 
a

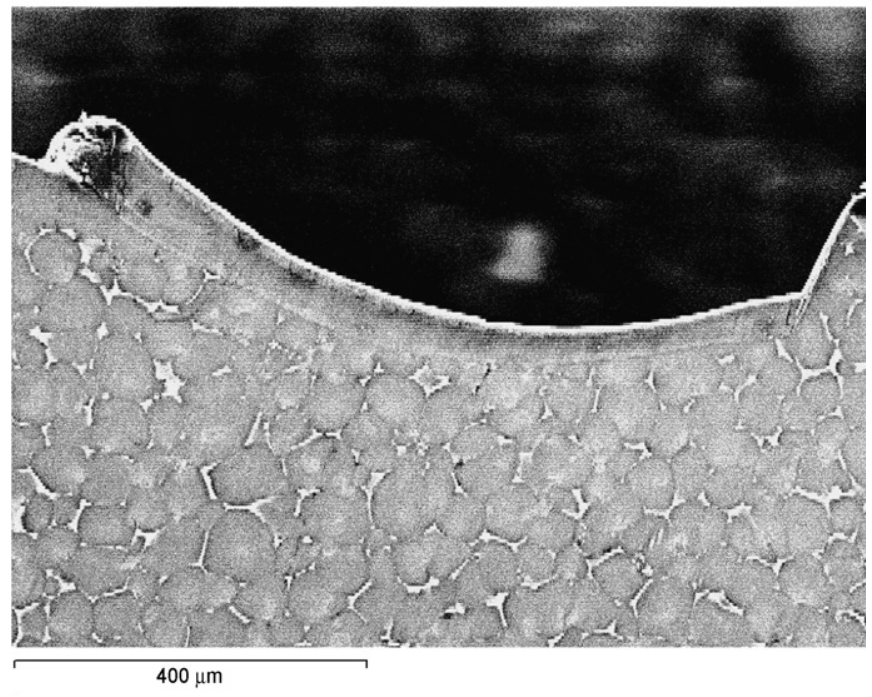

b

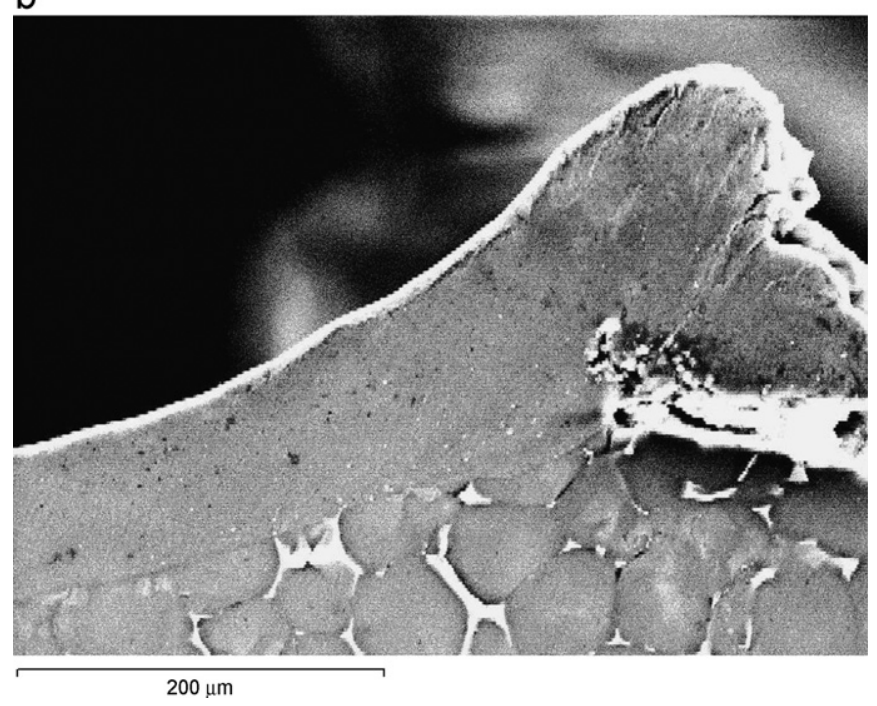

Fig. 5. SEM micrographs of laser-treated surface ZE 41 cross-sections, $V_{\mathrm{b}}=50 \mu \mathrm{m} \mathrm{s}^{-1}$.

time $\left(20 \times 10^{9} \mathrm{~ns}\right)$. A very thin layer melts and reaches high temperatures, while the surrounding mass of material is steel cold. Hence, the melted zone is subjected to a high cooling rate and there is not enough time for the heat affected zone to be formed.

\subsection{Microhardness improvement}

The microhardness of the treated specimen was measured within a laser and a non-laser-melted zone. These measurements are not taken with respect to the depth of the melted zone because it is too thin $(70 \mu \mathrm{m})$ to perform several indentations on it, but we carried out many measurements along the melted zone in the different laser tracks to see whether microhardness is uniform (see figure). Each indentation is done under a load of $0.49 \mathrm{~N}$ during $15 \mathrm{~s}$ with a Vickers indenter. Fig. 6 shows the microhardness measurements along the two zones. From this figure it can be observed that the microhardness of the lasertreated magnesium alloy is higher than that of the as-received specimen. The averages of the microhardness values in the laser-melted layer and in the bulk are respectively 124 and
$72 \mathrm{HV}$, these results are confirmed in two other samples treated in the same conditions. The laser surface melting treatment has improved the microhardness of the ZE41 by a factor of about $170 \%$. This improvement may be attributed, in the case of a crystalline material, to the grain refinement of the metallurgic structure and the homogenous distribution of the alloying elements in the magnesium matrix. The formation of new solid phases by precipitation can also increase microhardness. Whether the melted layer is amorphous, this non-ordered material can acquire better mechanical properties such as hardening.

\subsection{Corrosion resistance improvement}

Fig. 7 shows open-circuit corrosion potentials for the asreceived ZE41 and its laser-modified surface. This test was performed twice in a $0.5 \mathrm{M} \mathrm{NaCl}$ solution at $\mathrm{pH}=10$ and $293 \mathrm{~K}$. The open circuit potentials were recorded continuously for $24 \mathrm{~h}$ of immersion using a saturated calomel reference electrode. Comparing the two curves (Fig. 7), we can notice that the corrosion potentials of the alloy were increased by laser surface melting treatment by up to $117 \mathrm{mV}$ after $24 \mathrm{~h}$. Therefore, the laser-treated alloy became nobler than the untreated one [12]. This improvement in the corrosion resistance is confirmed twice by salt-spray tests carried out with respect to the ASTM B 117-97 standard. As shown in Fig. 8, a ZE41 specimen - presenting a $10 \times 10 \mathrm{~mm}^{2}$ laser-treated surface and a similar untreated surface - is exposed to a $\mathrm{KCl}$ salt spray ( 5 mass\% $\mathrm{KCl}$ solution, $\mathrm{pH}=6.9$ ) in a closed chamber maintained at $35^{\circ} \mathrm{C}$. After two hours of salt-spray exposure, several corrosion pits are observed in the untreated surface while the laser-treated layer is unaltered. Fig. 8 shows a completely corroded as-received alloy after $131 \mathrm{~h}$ of $\mathrm{KCl}$ spray exposure, although the treated surface is still intact. This better resistance to corrosion can be attributed to the microstructure transformations, due to rapid cooling of the lasermelted alloy [13]. These transformations lead to non-equilibrium microstructures which are more resistant to corrosion. The alloying elements added to the magnesium $\alpha$-phase matrix improve the resistance corrosion of the ZE41 alloy. In equilibrium microstructures, these elements are localized in grain boundaries because of their low solubility in the $\operatorname{Mg} \alpha$ phase. However, at high temperature, these alloying elements are more soluble in $\mathrm{Mg}$ and with a rapid cooling of the melted material, they are caught in the magnesium $\alpha$-phase which increases the concentrations of alloying element in the $\alpha$-solid solution and makes them much more efficient for corrosion protection of a ZE41 alloy. In addition, LSMT resulted in significant refinement of the granular microstructure due to the rapid cooling of the melted material producing therefore a more uniform distribution of the rare earth elements.

The cooling rate of the laser-melted layer plays an important role in microstructure transformations within the material. This cooling rate depends on the laser parameters such as laser energy pulse, laser scan speed, laser frequency and pulse duration. We noted in Section 3 (Fig. 3 ) the influence of the laser scan speed on the laser-melted layer depth, but SEM observations show that the melted zone has the same microstructure for the different laser scan speeds. The cooling rate of the material also depends on the boundary and initial conditions such as free or forced convection and initial material temperature. If these parameters change so that the cooling rate is slow, then the alloying elements uniformly dispersed in $\mathrm{Mg} \alpha$-phase at high temperature - are able to move to grain boundaries during the cooling process, which reduces their effect in enhancing corrosion resistance. For these reasons, we performed laser surface melting treatments on two samples preheated to 373 and $673 \mathrm{~K}$. SEM observations 
a

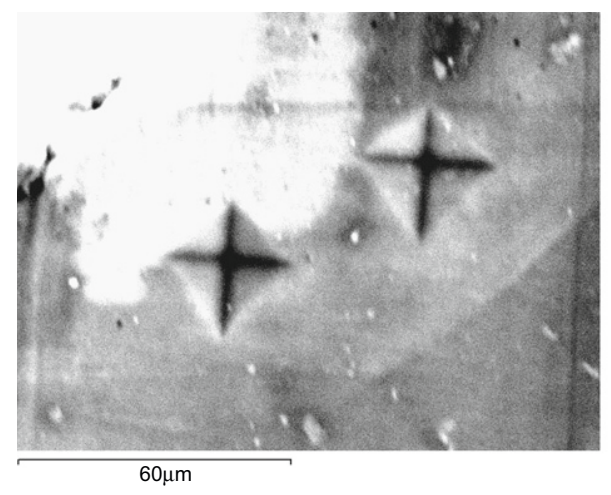

b

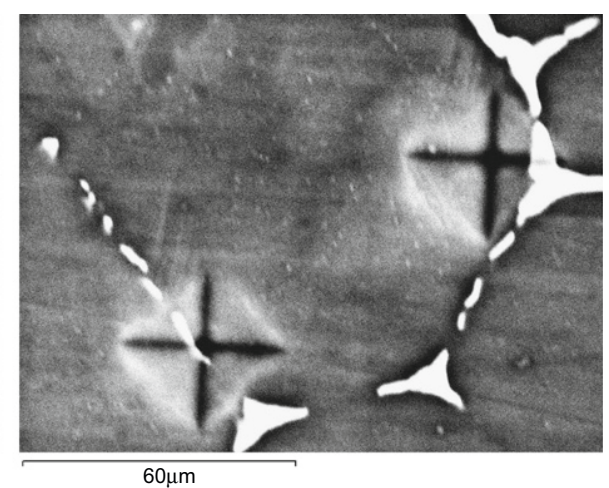

C

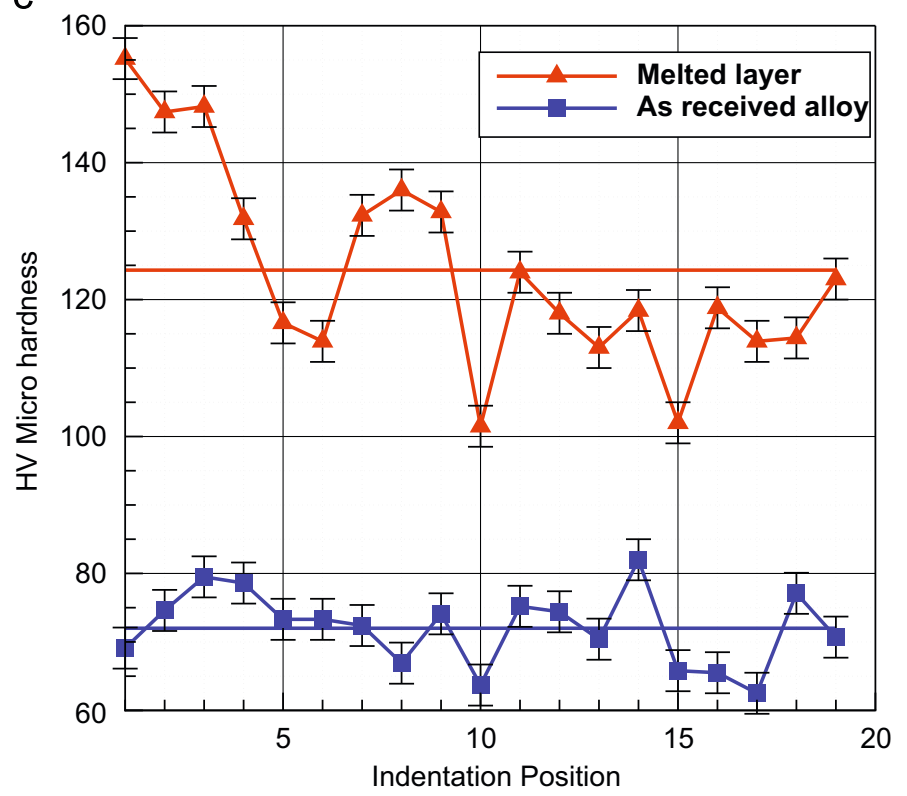

Fig. 6. Microhardness in the ZE41 laser-melted layer and in the substrate.

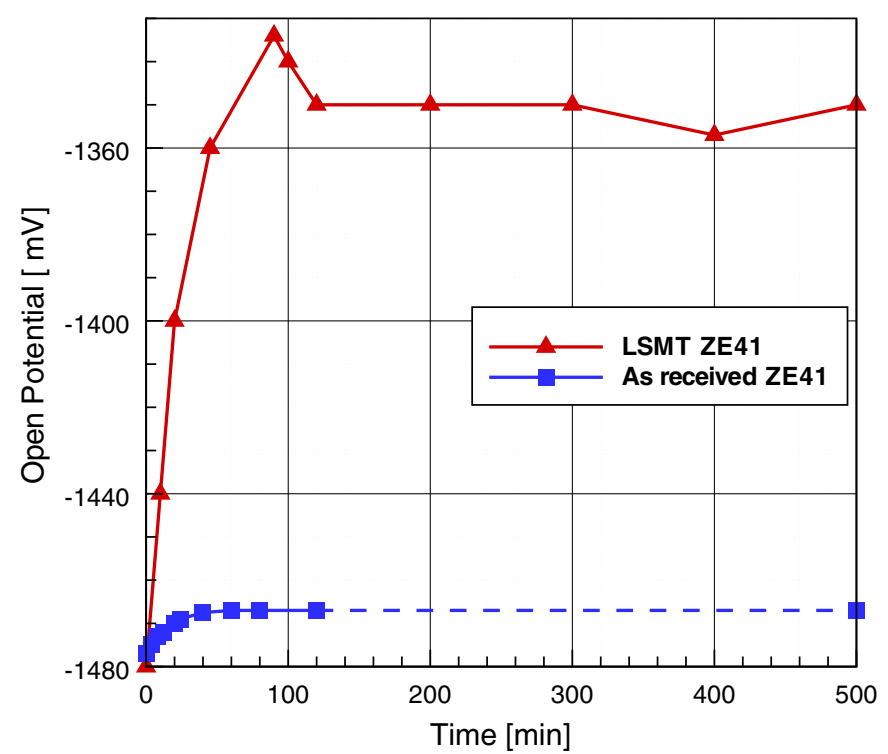

Fig. 7. Evolution of open-circuit potentials of LSM and as-received ZE41 alloy during immersion in $0.5 \mathrm{M} \mathrm{NaCl}$ solution of $\mathrm{pH} 10$ at $293 \mathrm{~K}$.

(not reported in this article) show no significant changes in preheated microstructures compared to non-preheated ones. Consequently, we can say that laser surface melting treatments carried out under the conditions mentioned above generate similar microstructures, and therefore similar resistance to corrosion.

As noted in Section 3.1, the laser-melted zone displays a rippled surface morphology with several asperities, especially in laser track borders (Figs. 4 and 5). These asperities can give rise to crevice corrosion [14]. Examining the sample after $24 \mathrm{~h}$ of immersion in a $0.5 \mathrm{M} \mathrm{NaCl}$ solution, we find that this surface was uniformly corroded. We cannot determine whether crevice corrosion took place or not. In addition, the salt-spray test shows that, after $131 \mathrm{~h}$ of exposure, the laser-treated surface is intact, and devoid of any sign of crevice corrosion. Knowing that the later type of corrosion needs an incubation time, after which the corrosion process begins to develop rapidly, this incubation time may be longer than $131 \mathrm{~h}$. Therefore we cannot detect it during the tests performed.

\section{Conclusion}

- A laser surface melting treatment of ZE41 Mg-alloy was carried out by a KrF excimer laser. Under fixed laser power and spot size, the depth of laser-melted layer depends on the scan speed of the laser beam. The maximum laser-melted layer depth reached in this study is $70 \mu \mathrm{m}$.

- The surface of the laser-treated magnesium alloy showed a wavy oxidized topography. 
a

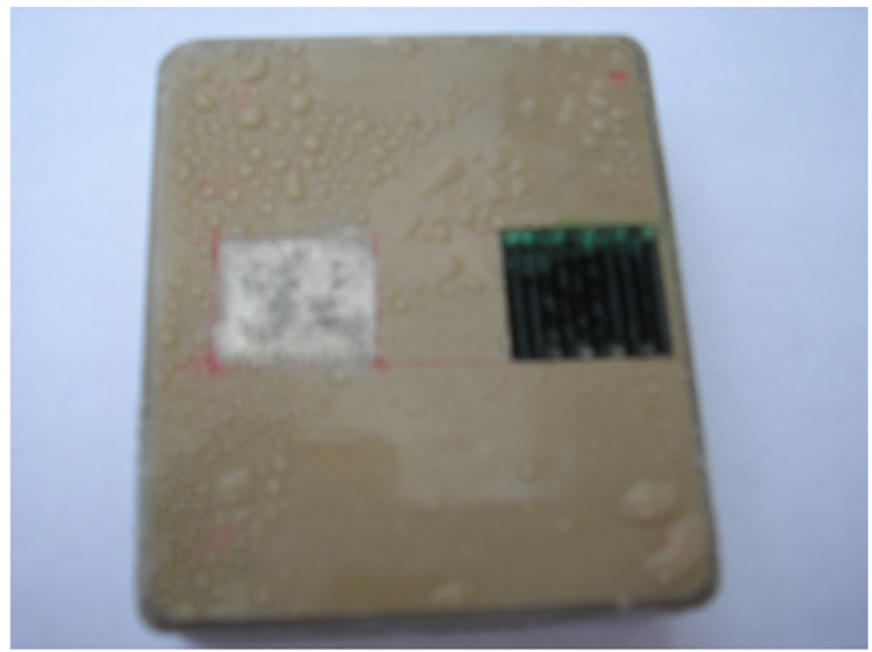

b

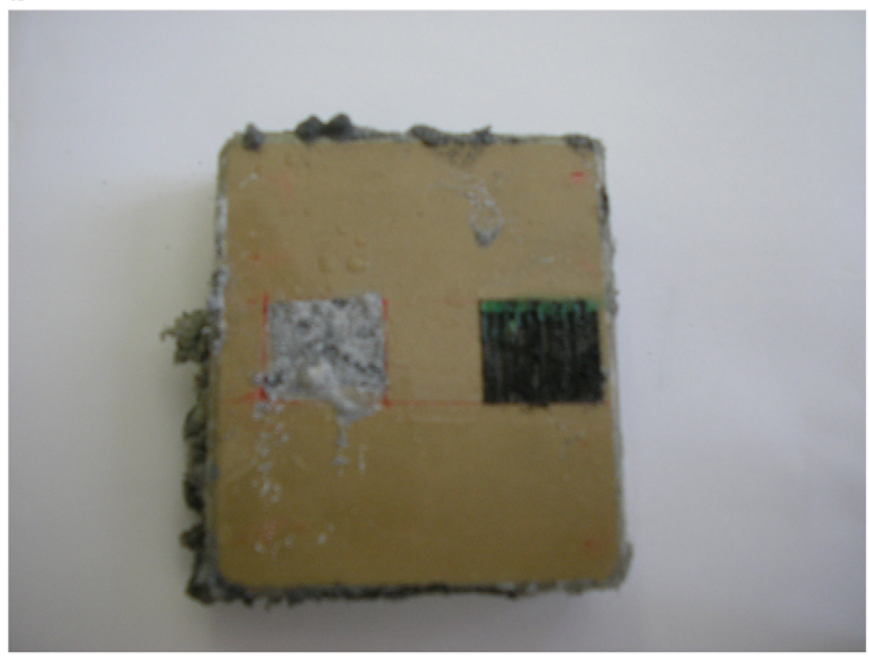

Fig. 8. Evolution of the corrosion in a salt-spray room of a LSMT and an asreceived ZE41 alloy: (a) after $2 \mathrm{~h}$ of exposure and (b) after $131 \mathrm{~h}$.

- The laser surface melting treatment resulted in significant refinement of the ZE41 microstructure.

- The laser surface melting treatment improved the microhardness of the ZE41 by a factor of about $170 \%$. This improvement may be attributed to the grain refinement of the metallurgic structure.

- The laser surface melting treatment of ZE41 improved the corrosion resistance in a $0.5 \mathrm{M} \mathrm{NaCl}$ solution of pH 10 at $293 \mathrm{~K}$ and under a salt-spray exposure. The improved corrosion behavior is associated with a refinement in the alloy's microstructure and the uniform distribution of alloying elements.

\section{Acknowledgements}

We would like to acknowledge the financial support of the "Conseil regional de PACA" and Protection des Métaux d'Arenc (PMA). The authors are grateful to PMA's engineers Ms. E. Castellan, Ms. A. Gonthier and Mr. F. Miretti for their help and assistance with the salt-spray tests.

\section{References}

[1] Kulekci MK. Magnesium and its alloys application in automotive industry. Int J Adv Manuf Technol 2008;39:851-65.

[2] Friedrich HE, Mordike BL. Magnesium technology. Berlin: Springer; 2006. (p. 431-97).

[3] Kalimullin RK, Valuev VV, Berdnikov AT. Structure and corrosion resistance of an $\mathrm{Mg}-\mathrm{Li}$ base alloy after laser treatment. Met Sci Heat Treat 1986;28: 668-70.

[4] Koutsomichalis A, Saettas L, Badekas H. Laser treatment of magnesium. J Mater Sci 1994;29:6543-7.

[5] Dubé D, Fiset M, Couture A, Nakatsugawa I. Characterization and performance of laser melted AZ91D and AM60B. Mater Sci Eng A 2001;299:38-45.

[6] Majumdar JD, Galun R, Mordike BL, Manna I. Effect of laser surface melting on corrosion and wear resistance of a commercial magnesium alloy. Mater Sci Eng A 2003;361:119-29.

[7] Abbas G, Liu Z, Skeldon P. Corrosion behavior of laser-melted magnesium alloys. Appl Surf Sci 2005;247:347-53.

[8] Guo LF, Yue TM, Man HC. Excimer laser surface treatment of magnesium alloy WE43 for corrosion resistance improvement. J Mater Sci 2005;40: 3531-3533.

[9] Gao Y, Wang C, Yao M, Liu H. Corrosion behavior of laser melted AZ91HP magnesium alloy. Mater Corros 2007;58(6):463-6.

[10] Jun Y, Sun GP, Jia SS. Charaterization and wear resistance of laser surface melting AZ91D alloy. J Alloys Compd 2008;455:142-7.

[11] Zhang Y, Chen J, Lei W, Xv R. Effect of laser surface melting on friction and wear behavior of AM50 magnesium alloy. Surf Coat Technol 2008;202: 3175-9.

[12] Zhao MC, Liu M, Song GL, Atrens A. Influence of $\mathrm{pH}$ and chloride ion concentration on the corrosion of $\mathrm{Mg}$ alloy ZE41. Corros Sci 2008;50: 3168-78.

[13] Neil WC, Forsyth M, Howlett PC, Hutchinson CR, Hinton BRW. Corrosion of magnesium alloy ZE41 - the role of microstructural features. Corros Sci 2009;51:387-94.

[14] Ghali E, Dietzel W, Kainer KU. General and localized corrosion of magnesium alloys: a critical review. J Mater Eng Perform 2004;13:7-23. 